\title{
The anteromedial extrastriate complex is critical for the use of allocentric visual cues and in the retention of the Lashley III maze task in rats
}

\author{
SERGIO ESPINOZA-CIFUENTES ${ }^{\mathrm{a}}$ and MARC LEANDER ZEISE ${ }^{\mathrm{a}}$
}

${ }^{a}$ Facultad de Humanidades, Escuela de Psicología, Universidad de Santiago de Chile, Santiago, Chile

\begin{abstract}
The anteromedial extrastriate complex has been proposed to play an essential role in a spatial orientation system in rats. To gain more information about that possible role, in the present work, two questions were addressed:

1. Are allocentric visual cues relevant for acquisition of the orientation task in the Lashley III maze? 2. Is this integration of allocentric inputs in the anteromedial visual complex relevant in the retention of this test? While a control group of rats was trained keeping the maze in the same position, the experimental group was trained with the maze rotated counterclockwise by 144 degrees from session to session.

Control rats reached learning criterion significantly earlier and with less errors than the experimental ones $(\mathrm{p}<.05)$. After 11 sessions, rats of both groups received stereotaxic injections of ibotenic acid in the anteromedial complex. In the retention test one week after surgery, the control group, which had been able to learn using egocentric and allocentric visual cues, showed a greater deficit than the experimental animals $(\mathrm{p}<.05)$.

These results confirm the role of the anteromedial complex in the processing of visuospatial orientation tasks and demonstrate the integration of allocentric visual cues in the solution of those tasks.
\end{abstract}

Key terms: visuospatial memory; anteromedial extrastriate complex; Lashley III maze; ibotenic acid; rat.

\section{INTRODUCTION}

Studies of the visual system have provided valuable insight into the neural processes underlying our capabilities for navigating in our surroundings and recognizing objects in it. The interdependence of these tasks has been a matter of intense debate (for example "...it is our contention that, despite the protestations of phenomenology, visual perception and the visual control of action depend on functionally and neurally independent systems" (Milner and Goodale, 2006). In this context, it is interesting that the anteromedial and anterior parts of the rat occipital cortex, the AM complex (AMC), a structure formerly considered an area of purely visual reception and recognition because of its retinotopic organization, turned out to be an integrator of diverse input qualities. AMC is one of several retinotopically organized extrastriate visual areas located laterally (in register with Krieg's area 18a, 1946; or Zilles's Oc2L, 1985) and medially (Krieg's area 18; Zilles's Oc2M) to the primary visual area (striate cortex, area 17, Oc1, V1); Coogan and Burkhalter, 1982; Espinoza and Thomas, 1983; Montero, 1973; Montero, 1981; Montero,1993; Montero et al., 1973a; Olavarría and Montero,1984; Torrealba et al., 1984).

As to the functions of these areas, previous studies have shown that bilateral lesions involving $\mathrm{Oc} 2 \mathrm{~L}$ reduce visual pattern discrimination (Gallardo et al., 1979; Mc Daniel et al, 1982; Wortwein et al., 1994), while lesions in Oc2M induce 
severe deficit in learning a Lashley III maze (Pinto-Hamuy et al., 1975) or a visuosomatic conditioned response (PintoHamuy et al, 1987), in contrast to no learning impediment in rats with lesions in Oc2L. Further studies using ibotenic acid lesions (that leave passing axons intact) restricted to the rostral part of Oc2M, which includes the anteromedial and the anterior extrastriate areas (anteromedial extrastriate complex, AMC, Montero, 1993) result in visuospatial discrimination deficits (Sanchez et al., 1997) and in a deficit in the acquisition of a visuospatial reference memory task in the Morris water-maze (Espinoza et al., 1999).

Further, it was demonstrated that, when deprived of parts of the AMC, blind rats show seriously reduced performance in their retention capacity tested in the Lashley III maze and that this reduction is tightly correlated to the extension of the lesion, while no deficit is observed in control rats bearing comparable lesions in V1 (Pinto-Hamuy et al., 2004). Thus, the AMC appears to integrate information from various sensory origins and for learning and retention processes in orientation tasks.

We wondered whether the AMC would also process inputs that are out of reach for the animal and therefore cannot be modified by its behavioral flow (allocentric stimuli as opposed to egocentric ones). Further, we asked whether those stimuli, once integrated in the system would be important to resolve a visual orientation task and whether the intact AMC would be critical for this. To address these questions we designed two experiments:

In the first, we used the Lashley III maze without cover or wire mesh, allowing free visual access to panels and other distant patterns in two groups of rats, impeding the use of those cues in the experimental group by rotating the whole maze after each session while the maze for the control group remained in the same position.

In a second experiment, all rats underwent ibotenic acid lesions that spare axons running through the structure in the AMC to see how their retention of the learned task might be affected.
METHODS

\section{Subjects}

Two groups of adult male hooded rats (Rattus norvegicus), of 230 to $310 \mathrm{~g}$ body weight, were used. The control group $(\mathrm{N}=9)$ was trained with the maze always in the same position, while the experimental group $(\mathrm{N}=9)$ was trained with the maze rotated $144^{\circ}$ counterclockwise (Fig. 1 B) before each session.

\section{Apparatus}

The Lashley III maze was used without cover. Otherwise it was the unchanged original (LASHLEY, 1943), with an entrance box, a goal box, eight blind alleys and five decision points (Fig. 1A). Start and goal boxes were equipped with a sliding door. The apparatus was placed in a room with some panels, drawings and pictures on the walls to provide distal visual cues. Training consisted of one daily session, 5 days a week.

\section{Learning procedure and retention test}

To motivate the animals, they were kept without drinking water during $22 \mathrm{hrs}$ before the training session and rewarded in the goal box with water. They were allowed one trail in the session, counting the errors. It was considered an error when animals entered with their entire body (except the tail) into a blind alley ("forward error") or made a return to the start box ("backward error"). The learning criterion was no more than one error in two consecutive sessions. After 11 sessions all animals had reached criterion and underwent lesion surgery.

Seven days after the operation, the retention test was performed. In this session the maze was oriented as in the position for controls (initial orientation for the experimental group).

\section{Surgery}

Fifteen minutes after injection of atropine $(0.4 \mathrm{mg} / \mathrm{kg}$, i. p.), subjects were anesthetized with sodium pentobarbital (60 
$\mathrm{mg} / \mathrm{kg}$, i.p.). The scalp was shaved and scrubbed with a $10 \%$ iodine solution. After a midline incision, the posterior neocortex was exposed through trephine holes.

Ibotenic acid (from Sigma; $15 \mu \mathrm{g} / \mu \mathrm{l}$ in saline; $\mathrm{pH} 7.4$; volume $0.5 \mu \mathrm{l}$; speed $0.2 \mu \mathrm{l} /$ $20 \mathrm{~s})$ was bilaterally injected through a 10 ul Hamilton syringe at stereotaxic coordinates $\mathrm{ML}=3.4 \mathrm{~mm}$ and $\mathrm{AP}=4.8$ $\mathrm{mm}$ (interaural line, $\mathrm{AP}=0 \mathrm{~mm}$ ) at a depth of $700 \mu \mathrm{m}$ from the cortical surface. These coordinates were derived from previous electrophysiological experiments and cytoarchitectonic data (Espinoza and Thomas, 1983; Montero et al., 1973b; Zilles, 1985).
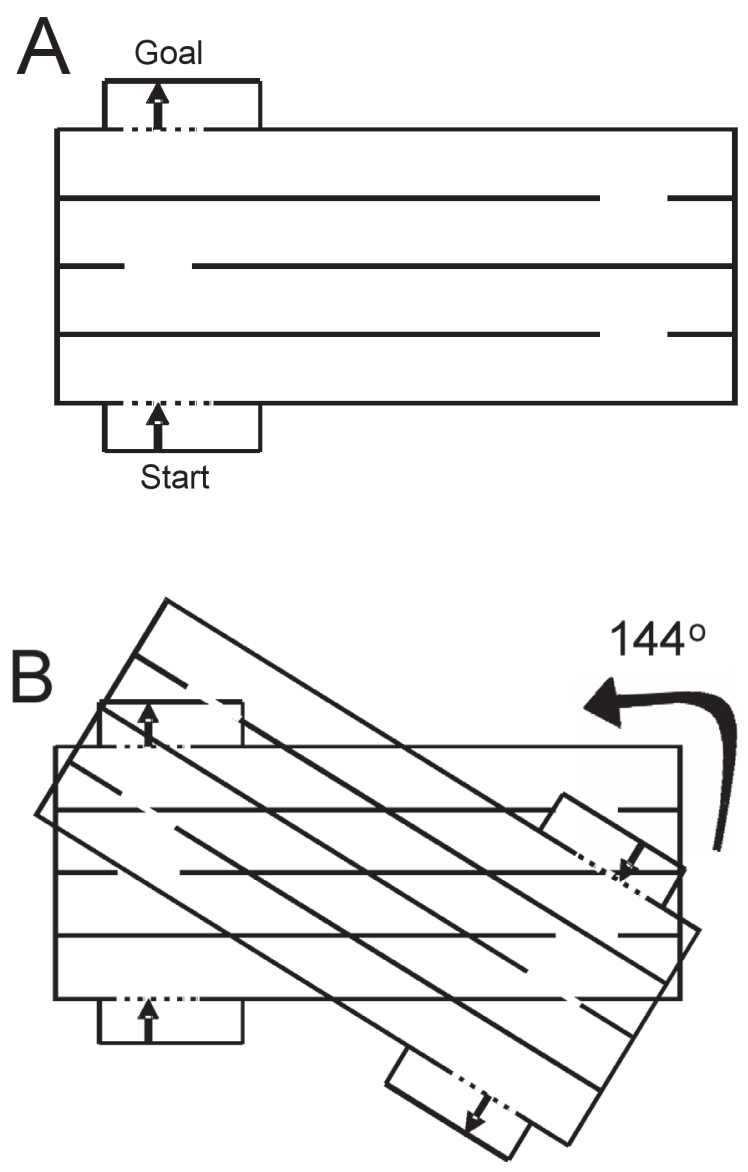

Figure 1: A: Schematic view of the Lashley III maze (from above). B: Illustration of the rotation that was performed after each session in the experimental group.

\section{Histology}

After the retention test the animals were sacrificed by an overdose of sodium pentobarbital and perfused through the heart with normal saline followed by $10 \%$ formalin buffered solution. Frozen coronal sections were cut at $60 \mu \mathrm{m}$. Every fifth section was mounted and stained with Cresyl violet.

\section{Reconstruction of the lesions}

The procedure was the same as used in our previous studies (Sánchez et al, 1997, Espinoza et al, 1999). The sections were examined with a light microscope. The lesioned cortical tissue was identified considering absence of neurons and presence of gliosis. Compromise of white matter was not observed in any of the lesions. The extension of the lesion was located in drawings enlarged tenfold obtained from optical projections. The drawings were used to produce a dorsal view reconstruction of the lesions by projecting the medial and lateral limit of the lesion on a standard dorsal view of the rat brain. The stereotaxic atlases of Paxinos and Watson (1982) and Zilles (1985) were used to estimate the antero-posterior level of the sections. The location of the AMC on this map was estimated on the basis of electrophysiological maps (Espinoza and Thomas, 1983; Montero et al., 1973b). The symmetrically lesioned area was calculated superimposing the compromised area of each hemisphere using a Sigma $\mathrm{Scan}^{\mathrm{TM}}$ measurement system (Jandel Scientific; Table I and Fig. 3). For practical purposes, the caudal limit of AMC was estimated from $\mathrm{AP}=4 \mathrm{~mm}$, interaural line $=0$, following the electrophysiological maps already referred to. Some individuals did not survive the operation and others were detected to have incorrect or insufficient lesions and, consequently, were excluded from evaluation.

\section{Statistics}

The Student's $t$-test was applied comparing the mean error for each group in each session. 
In the retention experiment, the mean errors for the two groups were compared using the Mann-Whitney test.

\section{RESULTS}

\section{Acquisition}

The animals of the control group, exposed to stable surroundings, reached criterion in 8 sessions or less (average $6.6 \pm 1.8$ (S.D.)), while the experimental animals that viewed distant visual stimuli rotated with each session, needed maximally11 (average $9.9 \pm$ 0.9 (S.D.)) sessions (Fig. 2). The difference between these average values was significant (independent samples $t$-test; $\mathrm{p}=$ $0.025)$.
Since conditions were identical for both groups in the first session, errors in this session were not counted. In the remaining 10 sessions, the control group made a total of 117 (average $13.0 \pm 7.5(\mathrm{SD})$ ) and the experimental group 199 (average $22.1 \pm 9.0$ (SD)) errors. That difference was also significant, although slightly less so than the former one $(\mathrm{p}=0.03)$.

\section{Morphological results}

Fig. 3 shows a dorsolateral view of the brains for both groups, the lesions depicted in black. The percentage of bilateral symmetrical lesion of area AMC is indicated for each rat (Fig. 3 and Table I). The solid horizontal line approximates the caudal limit of AMC.

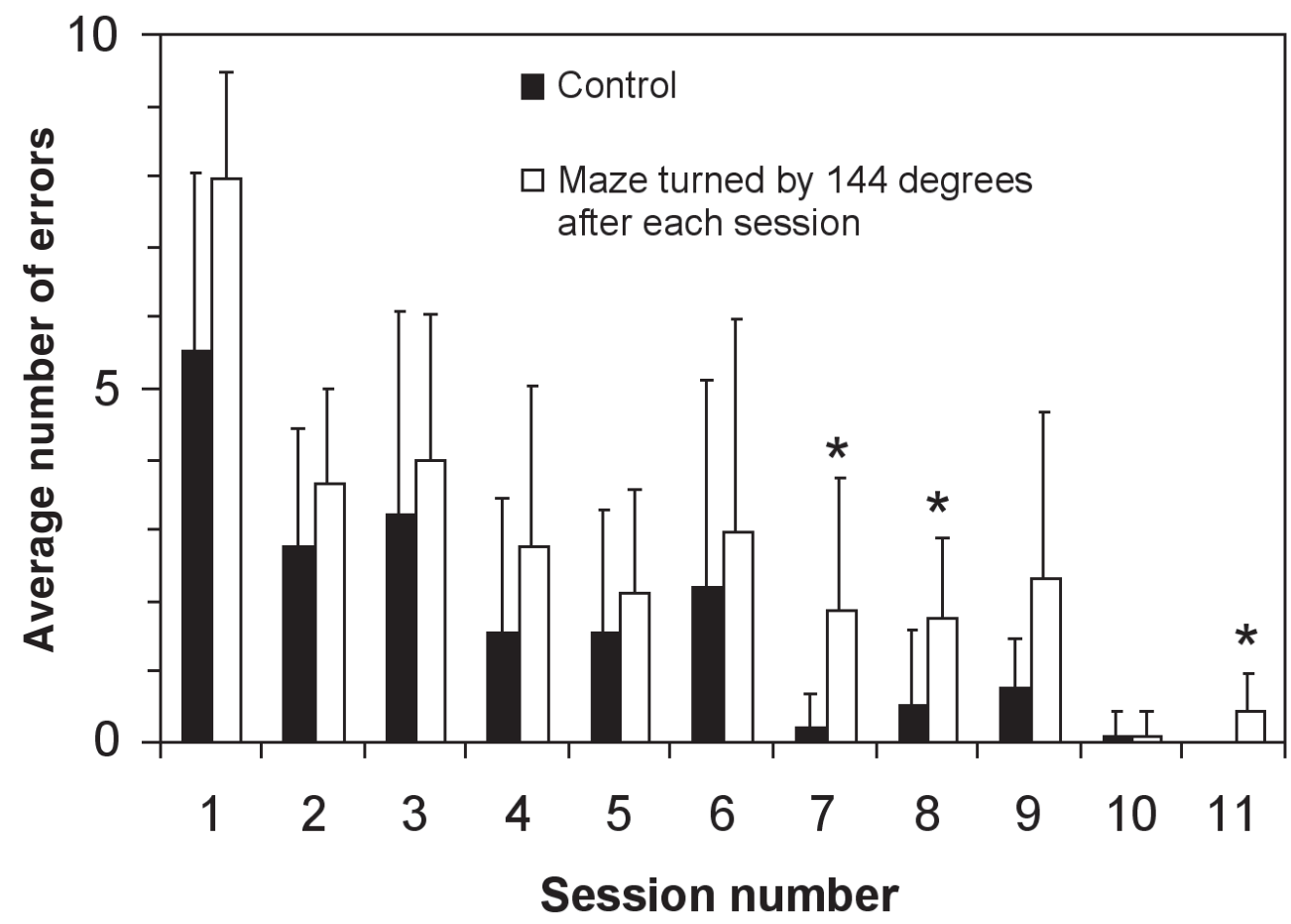

Figure 2: Allocentric orientation helps to resolve the Lashley III maze test: Control animals were able to use visual marks outside the maze for orientation, whereas the experimental group could not, being confronted with a changed outside scene caused by rotating the maze by 144 degrees after each session ( $\mathrm{n}=9$ for either group). Average number of errors are plotted against number of consecutive sessions (error bars: S.E.M.). Number of errors (total $117 v s .199$ excluding first session; average number of errors per session: $13.0 \pm 7.5$ S.D. vs. $22.1 \pm 9.0$ S.D.) and number of sessions to reach criterion were significantly different $(6.6 \pm 1.8$ S.D. vs. $9.9 \pm 0.9$ S. D.; $\mathrm{p}<0.05$ ). (Asterisk: significant difference in number of errors between groups in individual sessions; $\mathrm{p}<0.05)$ 
A. CONTROL C 3

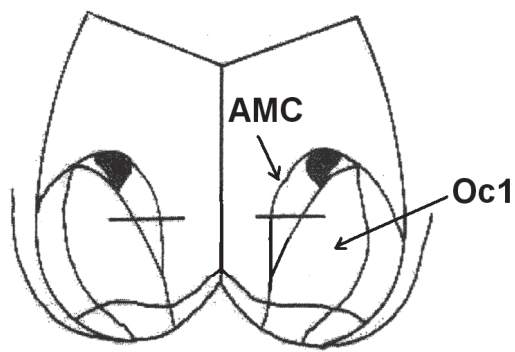

C5

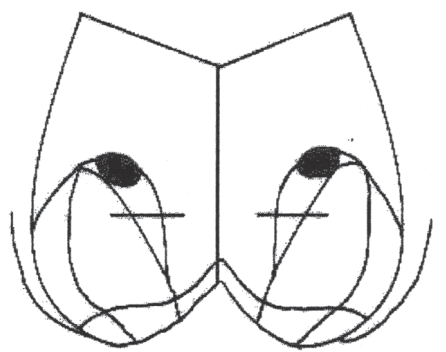

c 6

$41 \%$

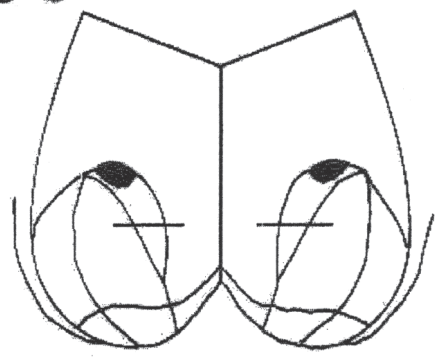

C 8

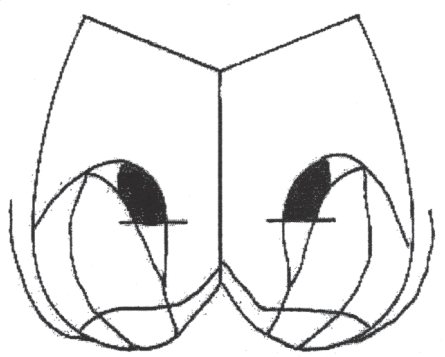

$82 \%$
B. EXPERIMENTAL

E1
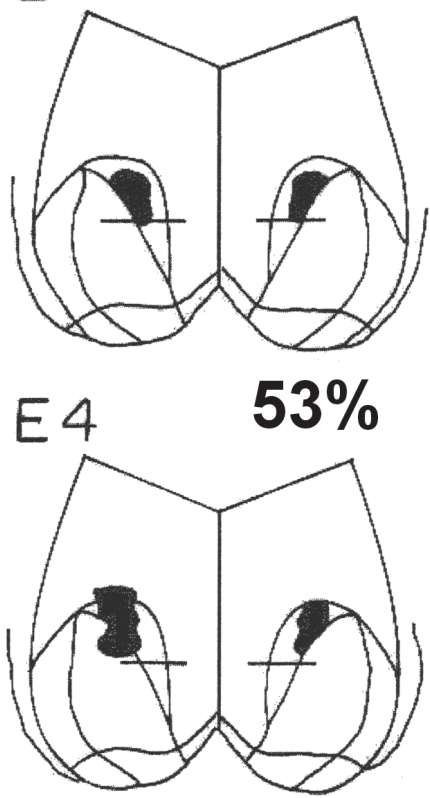

E $8 \quad 40 \%$
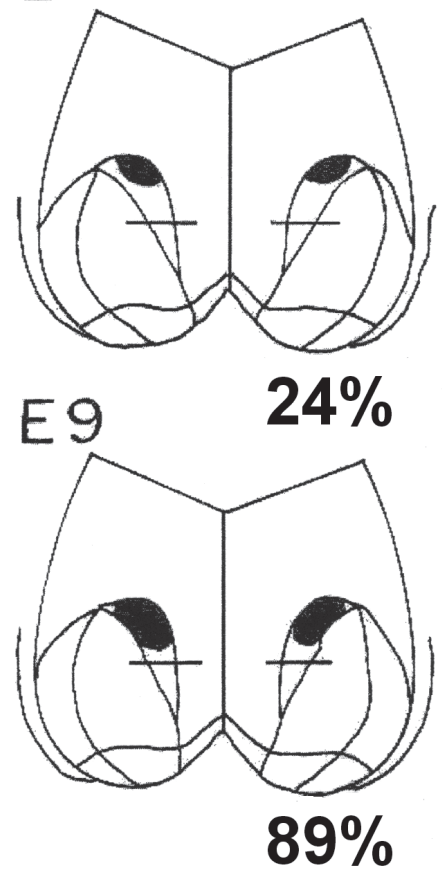

Figure 3: Histological reconstruction of the ibotenic acid lesions in the anteromedial complex (AMC) in control and experimental animals (dorsal view of the brains). In order to show the locations of the lesions, these are marked in black for each subject (letter and numbers of identification are identical to the ones shown in Table 1). In brain C3, AMC and Oc1 (primary visual area) are indicated. The horizontal line approximates the caudal limit of AMC, for practical purposes it was estimated at $\mathrm{AP}=4 \mathrm{~mm}$ and interaural line $=0$, following electrophysiological mapping data (Espinoza and Thomas, 1983; Montero et al, 1973b). 


\section{TABLE I}

Absolute and relative size of lesions in the anteromedial complex (AMC). Lesion areas were slightly, but not significantly, larger in experimental compared to control animals. Number of animals in both groups had been reduced from 9 to 4 by exclusion (inadequate lesion ( 3 controls/ 4 experimental) and death $(2$ controls $/ 1$ experimental).

\begin{tabular}{lcc}
\hline $\mathrm{N}^{\mathrm{o}}$ of animal & $\begin{array}{c}\text { Lesion area } \\
\left(\mathrm{mm}^{2}\right)\end{array}$ & $\begin{array}{c}\text { \% of AMC } \\
\left(1.75 \mathrm{~mm}^{2}\right)\end{array}$ \\
\hline C 3 & 0.34 & 19.4 \\
C 5 & 0.72 & 41.1 \\
C 6 & 0.41 & 23.4 \\
C 8 & 1.44 & 82.3 \\
Average of controls & $\mathbf{0 . 7 3}$ & $\mathbf{4 1 . 6}$ \\
& & \\
E 1 & 0.93 & 53.1 \\
E 4 & 0.7 & 40.0 \\
E 8 & 0.43 & 24.6 \\
E 9 & 1.56 & 89.1 \\
Average of experimentals & $\mathbf{0 . 9 1}$ & $\mathbf{5 1 . 7}$ \\
\hline
\end{tabular}

\section{Retention}

Retention was tested seven days after surgery for both groups in one session.

The experimental group $(\mathrm{N}=4)$ made a total of 2 errors (average $=0.5)$, the controls $(n=4)$ a total of 19 (average = 4.75). This difference was significant (Mann-Whitney test; $\mathrm{p}=0.03$ ).

Most errors in the control group consisted in returning to the start box ("backward errors").

\section{DISCUSSION}

The present results show that the AMC is critical for processing allocentic visual inputs in an orientation task. We have shown that distant visual stimuli are in fact used for the orientation task, reducing the number of sessions to reach criterion as well as the number of errors committed during the learning phase. The AMC is critical for that integration because lesions in that area are more compromising for the group of control animals who could use allocentric cues compared to those who could not.

Recently, Pinto-Hamuy et al., (2004) demonstrated that blind rats, when lesioned in the AMC, have more problems in the retention of the Lashey III maze task than blind controls lesioned in V1, the extension of the lesion being closely correlated to performance. Taken together with these findings, our data favor the notion that this structure may have the task of integration of information from diverse sensory origins and diverse character participating in orientation, memory storage and retrieval.

These results may also be regarded as a direct corroboration of our previous findings using the Morris Water Maze, showing that similar AMC lesions in the same strain of animals as used in the present work was critical, producing a severe deficit in the solution of a task in which the animals had to rely on distal visual cues for navigation (Espinoza et al., 1999).

We suggest that the retinotopy of area AMC is perfectly suited to deal with distal cues, since the receptive fields are considerably larger and with no overrepresentation of the central visual field as those in V1 (Espinoza and Thomas, 1983, Montero et al., 1973b). The present findings are in line with this former result.

In the second part of our experiment, the retention test, the rats of the control group made mainly "backward errors" (they returned to the start box) in contrast to errors in the direction to the goal box ("forward errors"). Backward errors characterized the initial two to three preoperative learning sessions while the forward errors were more frequent towards the final sessions, so that the control rats with the AMC lesions showed a lack of orientation and behaved as if they were relearning the maze. The experimental group in contrast made almost no errors. This observation supports the idea mentioned above that the AMC may be considered as part of a system for spatial orientation learning, memory and retrieval. 
As to how the AM complex participates in spatial memory mechanisms, there is evidence of a subpopulation of electrophysiologically recorded cells that code mnemonically for directional movement and spatial representations on the basis of visual cues (Chen et al., 1994; McNaughton et al., 1989). Probable neural pathways in rats comprise reciprocal connections of AMC to the retrosplenial cortex (Sanderson et al., 1991;. Torrealba et al.,1984; Vogt and Miller, 1983) and between the retrosplenial cortex and the hippocampal formation (Wyss and VanGroen, 1992). The hippocampus is implicated in episodic and spatial memory (Rolls, 2000) and contains cells that code for spatial location, the so-called 'place cells' (O'Keefe and Dostrovsky, 1971).

The results show once again the efficacy of restricted ibotenic acid lesion in the induction of a deficit that can be specifically ascribed to neuronal damage in the extrastriate AMC and not to spurious contamination of passing fibers. This method is a valuable tool for analysis of cortical function as was shown with similar lesions in the MT area in monkeys (Pasternak and Merigan, 1994).

Our findings confirm the importance of the rat $A M C$ as crucial for orientation, playing a role in spatial memory mechanisms, and thus can be regarded as homologous to the posterior parietal cortex (PPC) of monkeys (Kolb, 1990, PintoHamuy et al., 2004).

\section{ACKNOWLEDGMENTS}

The present work was conducted and supervised by Teresa Pinto-Hamuy who contributed with a first draft for its publication.

This work was supported by project S96081/2, DID, University of Chile to Teresa Pinto and Sergio Espinoza. The authors thank the medical students Pablo Guzman, René Jorquera and Solange Ramos for the efficient training of the animals, the recording of the behavioral data and Dr. Eugenia Díaz for the histological reconstructions. We also owe thanks to Dr. Fernando Torrealba and Dr. Luis Robles for the critical revision of an early version of this manuscript.

\section{REFERENCES}

CHEN LL, LIN LH , GREEN EJ, BARNES CA AND MCNAUGHTON BL (1994) Head-direction cells in the rat posterior cortex. I. Anatomical distribution and behavioral modulation. Exp Brain Res 101: 8-23

COOGAN TA AND BURKHALTER A (1993) Hierarchical organization of areas in rat visual cortex. J Neurosci 13: 3749-3772

ESPINOZA SG, THOMAS HC (1983) Retinotopic organization of striate and extrastriate visual cortex in the hooded rat. Brain Res 272: 137-144.

ESPINOZA S, PINTO-HAMUY T, PASSIG C, CARREÑO F, MARCHANT F, URZUA C (1999) Deficit in the Water-Maze after lesions in the anteromedial extrastriate cortex in rats. Physiol Behav 66: 493-496

GALLARDO L, MOTTLES M, VERA L, CARRASCO MA, TORREALBA F, MONTERO VM, PINTOHAMUY T (1979) Failure by rats to learn a visual conditional discrimination after lateral peristriate cortical lesions. Physiol Psychol 7: 173-177.

KRIEG WJS (1946) Connections of the cerebral cortex. I. The albino rat. A. Topography of the cortical areas, J Comp Neurol 84: 221-276 B Structure of the cortical areas J Comp Neurol 84: 277-284.

LASHLEY KS (1943) Studies of cerebral function in learning. XII. Loss of the maze habit after occipital lesions in blind rats. J Comp Neurol 79: 431- 462

MC DANIEL WF, COLEMAN J, LINDSAY JFJ (1982) A comparison of lateral peristriate and striate neocortical ablations in the rat. Behav Brain Res 6: 249-272.

MCNAUGHTON BL, LEONARD B AND CHEN L (1989) Cortical-hippocampal interactions and cognitive mapping: a hypothesis based on reintegration of the parietal and inferotemporal pathways for visual processing. Psychobiology 17: 230-235.

MONTERO VM (1973) Evoked responses in the rat's visual cortex to contralateral, ipsilateral, and restricted photic stimulation. Brain Res: 53: 192-196.

MONTERO VM (1989) Comparative studies on the visual cortex. In: Woolsey $\mathrm{CN}$, editor. Cortical sensory organization, vol. 2. Multiple visual areas. Clifton, NJ: The Humana Press; p. 33-81.

MONTERO VM (1993) Retinotopy of cortical connections between the striate cortex and extrastriate visual areas in the brain. Exp Brain Res 94: 1-15.

MONTERO VM, BRAVO H and FERNÁNDEZ V (1973a) Striate-peristriate cortico-cortical connections in the albino and gray rat. Brain Res 53: 202-207.

MONTERO VM, ROJAS A, TORREALBA F (1973b) Retinotopic organization of the striate and peristriate visual cortex in the albino rat. Brain Res 53: 197-201.

MILNER AD AND GOODALE MA (2006) The Visual Brain in Action, $2^{\text {nd }}$ Edition, Oxford, Oxford University Press, p. 1.

O'KEEFE J AND DOSTROVSKY J (1971) The hippocampus as a spatial map. Preliminary evidence from unit activity in the freely moving rat. Brain Res. 34: 171-175.

OLAVARRÍA J AND MONTERO VM (1984) Relation of callosal and striate-extrastriate cortical connections in 
the rat: morphological definition of extrastriate visual areas. Exp Brain Res 54: 240-252.

KOLB B (1990) Posterior parietal and temporal association cortex. In: Kolb B, Tees RC, Editors. The cerebral cortex of the rat. Cambridge, MA: The MIT Press; pp $459-71$.

PAXINOS G AND WATSON C (1982) The rat brain in stereotaxic coordinates. New York: Academic Press

PASTERNAK T AND MERIGAN WH. (1994) Motion perception following lesions of the superior temporal sulcus in the monkey. Cerebral Cortex 4: 427-259.

PINTO-HAMUY T, PUGA AM, SANDFORD A (1975) Behavioral analysis of peristriate cortex in the rat. Exp Brain Res Suppl 23: R469.

PINTO-HAMUY T, OLAVARRÍA J, GUIC-ROBLES E, MORGUES M, NASSAL O, PETIT D. (1987) Rats with lesions in anteromedial extrastriate cortex fail to learn a visuosomatic conditional response. Behavioral Brain Research 25: 221-231

PINTO-HAMUY T, MONTERO VM, TORREALBA $\mathrm{F}$ (2004) Neurotoxic lesion of anteromedial/posterior parietal cortex disrupts spatial maze memory in blind rats. Behavioral Brain Research 153: 465-470.

ROLLS ET (2000) Memory systems in the brain. Annu. Rev. Psychol. 51: 599-630.
SÁNCHEZ RF, MONTERO VM, ESPINOZA SG, DÍAZ E, CANITROT M, PINTO-HAMUY T (1997) Visuospatial discrimination deficit in rats after ibotenate lesions in anteromedial visual cortex. Physiol Behav 62: 989-994.

SANDERSON KJ, DREHER B AND GAYER N (1991) Prosencephalic connections of striate and extrastriate areas of rat visual cortex. Exp. Brain Res. 85: 324-334.

TORREALBA F, OLAVARRIA J, CARRASCO MA (1984) Cortical connections of the anteromedial extrastriate visual cortex in the rat. Exp Brain Res 56: 543-549.

VOGT BA AND MILLER MW (1983) Cortical connections between rat cingulate cortex and visual, motor and postsubicular cortices. J. Comp. Neurol 216: $192-210$

WORTWEIN G, MOGENSEN J, WIILIAMS G, CARLOS JH, DIVAC I (1994) Cortical area in the rat that mediates visual pattern discrimination.. Acta Neurobiol Exp 54: 365-376.

WYSS JM AND VANGROEN T (1992) Connections between the retrosplenial cortex and the hippocampal formation in the rat: a review. Hippocampus 2: 1-11.

ZILLES K (1985) The Cortex of the Rat. A Stereotaxic Atlas. Berlin: Springer-Verlag. 